\title{
Pável Filónov versus Pablo Ruiz Picasso
}

\author{
Antonia Miguel Fernández \\ Departamento de Historia del Arte, Universidad de Málaga, España (amiguelfernndez@ gmail.com)
}

Recibido el 15 de Noviembre de 2016; revisado el 18 de Diciembre de 2016; aceptado el 31 de Diciembre de 2016; publicado el 1 de Marzo de 2017.

RESUMEN: Aunque el título del artículo parece aludir a la oposición entre ambos artistas, el análisis de sus vidas y obra evidencia que, aunque sus figuras son en gran medida contrapuestas, también poseen características que los unen. No obstante, dados los límites del presente trabajo, sólo vamos a detenernos en tres cuestiones: la firma, su relación con las mujeres y los retratos de familia. No nos parece adecuado tratar la cuestión atendiendo a la importancia que la posición social o su origen oriental u occidental poseen en la producción artística de uno u otro, por una cuestión en la que están de acuerdo todos los estudiosos de la obra de Filónov: su obra es tan absolutamente extraordinaria y original, que se encuentra al margen, no sólo de las vanguardias occidentales, sino de las propiamente rusas. Es un artista único, que creó un estilo único, "el arte analítico" y una escuela propia y, por tanto, sin parangón con ningún otro.

PALABRAS CLAVE: Filonov, Vanguardia rusa, Picasso, Pintura, Arte analítico, Retrato.

\begin{abstract}
Although the title of the article seems to allude to the opposition between the two artists, the analysis of their lives and work shows that, even though their figures are largely opposed, they also possess characteristics that unite them. However, given the limits of the present work, we are only going to dwell on three issues: their firm, their relationship with women and family portraits. It doesn't seem to be appropriate to deal with the question in the light of the importance which the social position or their eastern or western origin possess in the artistic production of one or the other, by an issue in which all the studious of Filónov 's work agree: his work is so utterly extraordinary and original that it finds itself on the margins not only of the western vanguards, but of the Russian ones. He is a unique artist, who created a unique style, "analytical art", and a school of his own and, therefore, unparalleled with no other.
\end{abstract}

KEYWORDS: Filonov, Russian vanguarde, Picasso, Painting, Analytical art, Portrait.

\section{La firma}

La primera cuestión a tratar es un hecho que puede pasar inadvertido, pero que posee una trascendencia extraordinaria, la firma. El único trabajo que no firmó Picasso, una vez vendido, fue El Guernica, por 
sus importantes implicaciones políticas. Sin embargo, todo su proceso de creación fue milimétricamente documentado por su pareja en aquél momento, la fotógrafa Dora Maar.

El pintor, como la gran mayoría de artistas desde el Renacimiento, otorgaba gran importancia a la firma, el más elemental medio de reconocimiento de su obra, de hecho no firmaba sus trabajos hasta que los consideraba acabados. Su firma en sí misma se convirtió en un valor de arte (Aguilar, 2013, pp.199-218), y, tal llegó a ser su cotización, que regalaba servilletas con su firma, e incluso llegó a firmar en la piel de algunos de sus admiradores1, precedente del boom de los autógrafos en los años 60-70 y de los selfies con famosos en la actualidad (Pétard, 2015).

Por otra parte, Picasso no siempre firmó del mismo modo y, como nos ocurre a todos los seres humanos, su firma fue evolucionando a lo largo del tiempo:

-En su niñez (ha. 1881-1895) firma como "P. Ruíz", aunque a veces añade el apellido de su madre.

-En su adolescencia (ha. 1895-1901) no se detectan grandes cambios, firma con sus dos apellidos "P. Ruiz Picasso" e incluso lo reduce a "PR Picasso".

-A partir de 1901, ya en su madurez, empieza a firmar únicamente con el apellido de su madre. La gran mayoría de autores considera que con ello quería poner de manifiesto el rechazo a su padre, aunque otros lo achacan a que sus amigos de París le llamaban Picasso.

-Tras la Segunda Guerra Mundial se muestra una correspondencia entre su obra y el grafismo de su firma.

Frente a la necesidad de autoafirmación del malagueño universal a través de su firma, encontramos una actitud totalmente contrapuesta en Pável Filónov. En ninguna de las obras que hemos podido conocer a lo largo de esta investigación hemos encontrado su firma. A falta de que un día puedan publicarse en español la totalidad de sus diarios, sólo podemos intuir la razón de su consciente anonimato, que parece estar en conexión con el hecho de que nunca vendió ningún cuadro que no fuera un encargo, dado el convencimiento profundo de que su obra no le pertenecía y que era patrimonio del pueblo ruso (Petrova, 2015, p.14). Prueba de ello es que en 1931 escribió en tercera persona: “Todos sus trabajos, los ya hechos y los que tiene previsto hacer, los lega al Estado para que se funde el Museo del Arte Analítico. Quiere hacer una exposición de sus obras por la Unión y en el extranjero" lo que, en cumplimiento de su voluntad, fue realizado por su hermana (Petrova, 2015, p.14).

La triste realidad fue que, hasta 1989 no fue posible la realización de la primera exposición individual del artista, como no podía ser de otro modo, en el Museo Ruso de Leningrado y, posteriormente en Moscú, París y Dusseldorf (Durozoi, 2007, p.233), siendo la que se celebra actualmente en el Museo Ruso de Málaga, la primera que se realiza en nuestro país.

\footnotetext{
${ }^{1}$ Se cuenta que incluso no se llegaron a cobrar algunos cheques de su procedencia con tal de conservar su firma.
} 


\section{Relación con las mujeres}

\section{A) Picasso:}

Fueron muchas las mujeres que pasaron por su vida, pero sólo algunas de ellas influyeron de manera determinante en su obra (Izquierdo, 2004). Poseía una personalidad contradictoria y un fuerte carácter, a veces podía ser tierno, pero a la vez ejerció una influencia sumamente destructiva sobre las mismas. Sirvan de ejemplo las palabras de su madre, María Picasso, a Olga Koklova: "Oh, mi pobre pequeña, no sabes lo que te espera. Si yo fuera vuestra amiga os aconsejaría que no os casáseis. Creo que ninguna mujer puede ser feliz con mi hijo. Él no puede pertenecer a ninguna persona, porque él pertenece a la pintura".

A pesar de ello nunca supo vivir solo. De entre todas ellas las más influyentes fueron las siguientes: Germaine Pichot, a la que conoció en sus primeros años en París; Madelaine, amante de Picasso tras Germaine; Fernande Olivier con la que convive, a la vez que mantiene una relación con Madelaine; Eva Gouel, su compañera desde 1912 hasta que fallece en 1914; Olga Koklova, bailarina de la compañía rusa de Diaghilev, con la que obtuvo el triunfo social. En el año 1927, aun casado con Olga, conoce a Marie-Thérese Walter que tenía sólo 17 años. Dora Mar, mujer intelectual y gran fotógrafa; Francoise Gilot, pintora que conoce en 1943; y, por último, Jacqueline Roque, su segunda esposa, que conviviría con él hasta su muerte.

A excepción de Françoise Gilot, que le abandonó tras convivir con el pintor diez años, todas las demás mujeres sufrieron un sometimiento enfermizo al genio, y su efecto sobre ellas fue devastador; la rusa Olga Khoklova, que dejó la danza para entregarse en cuerpo y alma al artista, acabó neurótica por los celos y el abandono del artista; Marie-Thérese Walter se suicidó tras la muerte de Picasso y la fotógrafa Dora Maar acabó en un manicomio; por último, Jacqueline Roqué, el verdadero amor de Picasso, al no poder superar su muerte, también acabó suicidándose2.

Todas las biografías coinciden en la especial relación que mantuvo con su madre y la influencia extraordinaria que tuvo en su obra, sobre todo en sus primeros años como pintor. Además, al ser hijo único, vivió en un auténtico matriarcado marcado por su madre y sus dos hermanas, aunque la menor, Conchita, murió siendo muy niña, una muerte que afectó sobremanera al pintor3.

\section{B) Pável Filónov}

A diferencia de Picasso, el artista sobre el que se han publicado más libros, ensayos, artículos e investigaciones etc., en todo el mundo, son pocos los datos biográficos que poseemos de Filónov y de sus relaciones amorosas. A pesar de ello, ambos autores no pueden ser más contrapuestos también en este ámbito, mientras el primero encadenaba y hacía coincidir en el tiempo diversas relaciones, Filónov se mantuvo fiel y enamorado a su única mujer, Ekaterina Aleksándrovna Serebriakova, hasta su muerte en 1941, en el sitio de Leningrado, permaneciendo a su lado y cuidándola cuando ésta quedó

\footnotetext{
${ }^{2}$ http://www.arteyciudad.com/arte2o/documentos/doloresarroyo.htm (Consultado: 20/11/2015).

${ }^{3}$ http://fundacionpicasso.malaga.eu/export/sites/default/cultura/fpicasso/portal/menu/seccion_0008/documentos/LOS_PI CASSO.pdf (Consultado: 19/11/2015).
} 
impedida. Ella le correspondió en la misma medida, ya que, por mor de la persecución a la que el régimen le sometió, en 1938, los dos hijos de ella -Piotr y Anatoli Serebriakov- fueron arrestados y ambos murieron en los gulag. Además, Ekaterina fue obligada por las autoridades a firmar el compromiso de no salir de su ciudad (Petrova, 2015, p.13), y sufrió junto a él persecución política y dificultades económicas.

Nicoletta Misler alude a que existió un rumor en la familia que atribuía a un desengaño amoroso el cambio tan drástico que sufrió en el verano de 1910 (Llorens, 2006, p.65), un hecho que, aunque no parece plausible como causa del mismo, sí nos permite conocer que al menos estuvo enamorado en dicha fecha.

Las circunstancias en las que conoció a Ekaterina son, cuanto menos, sombrías. Tras la muerte de su marido, ésta contrata a Filónov para que realice un retrato post mortem del mismo y, en ese momento ambos se enamoran. Ella, a la que paradójicamente llamaba hija, tenía 58 años y Pável 20 años menos, una diferencia de edad que no impidió que se mantuvieran unidos hasta la muerte, a pesar de las muchas penalidades que sufrieron como consecuencia del carácter asceta del pintor y su negativa a vender ninguno de sus cuadros analíticos, cuadros cuya venta fuera de Rusia le habrían hecho millonario.

Al igual que Picasso vivió en un auténtico matriarcado, aunque en el caso de Filónov y tras su muerte, ese matriarcado protector se trasladaría a su obra, que fue preservada y conservada por su hermana, Eudokia Glebona, hasta que pudo donarla al Museo Ruso de San Petersburgo en 1977, tras el fin del régimen soviético, siguiendo la voluntad del artista. Según su hermana, la familia era muy pobre (Petrova, 2015, p.123), condición social que lo diferencia de Picasso, ya que éste era hijo de un pintor y profesor de pintura malagueño, perteneciente por tanto, a la escasa clase media de la época. Pero Filónov quedó huérfano de padre en 1887, con apenas cuatro años, y al poco tiempo también de madre. Ambos artistas son igualmente hijos únicos, aunque Filónov tenía tres hermanas.

En 1896, los hermanos se trasladan de Moscú a San Petersburgo, a la casa de su hermana mayor, Alejandra, que se convertirá en su segunda madre. Casada con un ingeniero que le proporcionó una vida acomodada, aunque la pobreza no se alejó para siempre de su vida. Su mujer se convertiría, a mi parecer, en una tercera madre para él. En ese matriarcado en el que transcurrió su vida, lo protegió siempre y durante años vivieron de lo poco que aportaba Filónov por su trabajo y de la pensión que Ekaterina percibía del Estado. Ella, que entiende su obra y comparte su vida de asceta, así como su idealismo humanista, fue la compañera perfecta para un artista como él, fiel a sí mismo y a su pintura. Baste como demostración una cita de Ekaterina que su cuñada recuerda en una de sus conversaciones con el Dr. Yuri Zverev:

"Las almas de todos los innovadores, revolucionarios, ideólogos de la verdad y del amor están en él. Él une las creaciones terrestres con las creaciones del mundo más allá de las estrellas -eso se siente en su nueva obra, donde el hombre alza su cara y sus manos hacia el infinito. Si él no hablara con los colores, que no entienden las masas, sino que hablara el idioma humano, cambiaría el mundo entero- llegaría el paraíso, ya que lo que lo movía fue el sufrimiento por la humanidad y el deseo de felicidad para todos. 
Nadie puede entender la obra de Filónov, porque llevan dentro la magnitud y el misterio del momento. Eso queda para el futuro, la historia descifrará sus cuadros" 4 .

Si la vida del artista transcurrió rodeado de mujeres, igual ocurrió a la hora de su muerte, e incluso en su entierro. En el momento de fallecer se encontraban junto a él su mujer, la nuera de ésta, María, y su hermana Eudokia, y a ellas se unieron en el entierro, su otra hermana viva, Alejandra y Raya, la sobrina de su mujer.

\section{Retratos de familia}

Filonov no realiza apenas retratos de su mujer ni del resto de su familia, un hecho coherente con su teoría del "arte analítico" y la consideración de que los artistas contemporáneos a él en el tiempo, atendían únicamente a dos de las propiedades de la naturaleza: el color y la forma, mientras él consideraba que la obra artística debe mostrar todos los procesos que se producen en la misma, los que "el ojo ve", y los invisibles, que sin embargo pueden ser captados por el "ojo que sabe", pero que, al no ser vistos, el artista ha de reflejarlos de un modo no figurativo, mediante la invención (Petrova, 2015, p.8). A pesar de sus palabras se sabe que estudió anatomía durante casi tres años y, de hecho, es el estudio de la anatomía lo que le hace cambiar de actitud hacia la naturaleza y con ello, su obra posterior (Llorens, 2006, p.67). Además, en algunas de sus obras, las formas son similares a cristales o a la sección de un tejido a través del microscopio, lo que denota el interés de Filónov por los efectos ópticos y cómo los nuevos avances científicos le ayudaron en su necesidad de mostrar lo "invisible" (Sierra, 1999, p.123).

A pesar de ello, se conocen tres retratos familiares, uno en el que aparece su hermana Eudokia, otro de su cuñado y sobrino y, el último un retrato familiar de 1924. Resulta, al menos curioso, que en ninguna de ellas recurra al arte analítico, siguiendo en todas un estilo figurativo, hiperrealista en el caso del cuñado desaparecido. En el retrato familiar aparece su mujer en segundo término, aunque ocupando uno de los lugares centrales de la acuarela, y destacada de tal modo que la mirada del espectador se dirige indefectiblemente a su rostro.

Los otros dos retratos, ambos realizados al óleo, atienden a parámetros clasicistas, el de su hermana Eudokia -según relató la misma al Dr. Zverev- porque ella exigió ser pintada a la manera clásica y, en vez de lienzo, utilizó un delantal de barrendero. El de su cuñado Armand Azibert con su hijo parece ser que fue realizado a partir de una fotografía, muy posiblemente tras su desaparición en la batalla del Marne (Petrova, 2015, p.46).

En todos ellos se aleja de sus investigaciones pictóricas, iniciadas mucho antes de la ejecución de estos retratos, sobre todo el familiar, que ejecuta en fecha muy tardía, probablemente porque lo único que le mueve a su realización es el cariño que siente hacia todos ellos y el propio gusto de los retratados.

\footnotetext{
${ }^{4}$ Documento no publicado del Dr. Yuri Zverev en el que relata cómo conoció a la hermana pequeña del pintor, Eudokia y como ésta custodió su obra hasta donarla al Museo ruso de Leningrado, además de proporcionarle importantes datos biográficos del artista.
} 
Picasso, por el contrario, pinta a sus mujeres en estilos diversos, aunque a su madre lo hace únicamente al modo clásico y, con su hermana Lola, lo más que se permite es utilizar el estilo modernista en el retrato que realiza en 1899. A diferencia de Filónov, Picasso realizó múltiples retratos de su entorno en los que se puede apreciar los múltiples cambios de su lenguaje pictórico a lo largo de su vida, además de mostrarnos en alguno de ellos una gran ternura, sobre todo en los que realiza a sus hijos y a Marie Therese Walter5. Precisamente, el Museo Picasso de nuestra ciudad, conmemorando el $\mathrm{X}$ aniversario de la apertura del museo, organizó una exposición del 24 de junio al 6 de octubre de 2013 denominada "Pablo Picasso. Álbum de familia" en el que se queda de manifiesto como los miembros de su familia fueron fundamentales en su obra y en la evolución de la misma (Lebrero, 2013).

\section{Conclusiones}

En el análisis realizado, las similitudes entre ambos artistas se producen dentro del ámbito familiar, y ello va a repercutir en sus obras respectivas. Ambos fueron hijos únicos y vivieron en un matriarcado desde su nacimiento, aunque la doble orfandad de Filónov produjo que encontrara una segunda madre en su hermana Alejandra, y una tercera en Ekaterina, su única mujer.

Por el contrario, encontramos profundas diferencias, tanto en el caso de la firma como en el número y trato dispensado a las mujeres que pasaron por su vida. Mientras Picasso mantuvo innumerables relaciones a lo largo de su vida, y convirtió la de sus mujeres en un auténtico infierno, Filónov permaneció hasta su muerte al lado de su esposa, a la que adoraba.

En los retratos familiares realizados por ambos también se producen posiciones contrapuestas, tanto en el número como en el lenguaje pictórico utilizado. Se conocen únicamente tres obras en el caso de Filónov y el lenguaje plástico utilizado en todos ellos está muy ligado al clasicismo. Picasso, por su parte, utilizó múltiples lenguajes pictóricos para representar a su familia, a la que retrató frecuentemente a lo largo de toda su vida.

\section{Referencias bibliográficas}

AGUILAR NUEVO, Rocío y LARA BARRANCO, Francisco (2013), "Negociando con la firma artística: De la creación de la marca al renacimiento del autor (1960-2010)", Cuadernos de Arte de la Universidad de Granada, n. ${ }^{\circ 4}$, pp.199-218.

ARROYO FERNÁNDEZ, María Dolores, "Musa y esposa: la inspiración del artista". http://www.arteyciudad.com/arte2o/documentos/doloresarroyo.htm (Consultado: 20/11/2015).

DUROZOI, G. (dir.) (2007), Diccionario Akal de arte del siglo XX, Akal, Madrid.

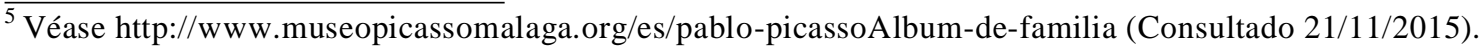


IZQUIERDO, Paula (2004), Picasso y las mujeres, Edit. Belacqua, Barcelona.

LEBRERO STALS, José (com.) (2013), Pablo Picasso. Álbum de familia. (exposición celebrada en Málaga, Museo Picasso, del 24 de junio a 6 de octubre de 2013) Fundación Museo Picasso Málaga, Málaga.

PÉTARD, Claire, Picasso, ¿identidad o máscara? http://mitopicasso.blogspot.com.es/2013/03/lapreciosa-firma-de-picasso-senal-de.html (Consultado 21/11/2015).

PETROVA, Yulia (com.) (2015), Testigo de lo invisible. Pável Filónov, (exposición celebrada en Málaga, Museo ruso del 14 de agosto de 2015 a enero de 1916), Agencia Pública para la gestión de la Casa Natal Pablo Ruíz Picasso y otros equipamientos culturales y museísticos, Ayuntamiento de Málaga.

SIERRA, Mrta (com.) (1999), El hombre, el aire, el espacio y Malevich y los maestros rusos de la vanguardia, (exposiciones celebradas en Palma de Mallorca, Casal Solleric y Centro de Cultura "Sa nostra" desde el 14 de mayo al 18 de julio de 1999), Ayuntamiento de Palma de Mallorca y Caja de Ahorros Sa Nostra.

http://fundacionpicasso.malaga.eu/export/sites/default/cultura/fpicasso/portal/menu/seccion_0008/do cumentos/LOS_PICASSO.pdf (Consultado: 19/11/2015)

http://www.museopicassomalaga.org/es/pablo-picassoAlbum-de-familia (Consultado 21/11/2015) 